\title{
Spectrum of Radiological Findings on Noncontrast Computed Tomography Head in a Trauma Center with Cases of Acute Head Injuries
}

\author{
${ }^{1}$ Piyush K Dhagat, ${ }^{2}$ Abhishek Dwivedi, ${ }^{3}$ Sumeet Arora, ${ }^{4}$ Satyender N Singh, ${ }^{5}$ Shalini Singh, ${ }^{6}$ Megha Jain
}

\begin{abstract}
Background: Noncontrast computed tomography (NCCT) head provides clinically and surgically important information in brain trauma. It can depict the severity, level, and prognosis of head injuries.
\end{abstract}

Aim: To depict the spectrum of NCCT-radiological findings in cases of head injuries at this center.

Material and methods: Noncontrast CT head examination of 518 patients were retrospectively included in the study for the duration of the year 2015 to 2016 and 2016 to 2017 by retrospective screening of the electronic report's data of last two years of about 7000 patients, who had history of head injury as well as NCCT evidence of head injuries and in whom surgical/ clinical follow-up for final diagnosis was available. CT scan was done in all the patients with Somatom Emotion CT (16 slices) Siemens medical systems. Patients included have presented with a history of head injuries and those who were brought for suspected head injuries. Postoperative patients and patients associated with other body parts injuries were excluded as the clinical outcomes of these patients could not be judged because of multiple system involvement.

Result: A total of 518 patients were taken among whom 355 were male, and 163 were female with age varies from 1 month to 92 years with a total number of deaths noticed in the study were 13. The road traffic accident was the commonest mode of injury. The radiological findings (contusion $15.2 \%$ and $3.1 \%$, diffuse axonal injury $2.3 \%$ and not reported any case, subarachnoid hemorrhage $13.6 \%$ and $4.9 \%$, extradural hemorrhage $8.7 \%$ and $3.1 \%$, subdural hemorrhage $15.5 \%$ and $11.7 \%$, skull fractures $29 \%$ and $18.4 \%$, midline shift $4.5 \%$ and $6.1 \%$, scalp hematoma $8.7 \%$ and $24.5 \%$ ) were seen in males and females respectively.

The cases associated with $>4$ radiological findings have more associated fatal outcomes than the cases with $<4$ radiological findings ( $p$-value $=0.0001)$.

Conclusion: The study enlightens the significant positive findings on the NCCT which is the fast easily available procedure and can be used for early diagnoses and management. Thus NCCT head helped in decreasing the mortality. The more

\footnotetext{
${ }^{1}$ Professor and HOD, ${ }^{2}$ Graded Specialist, ${ }^{3}$ Senior Advisor, ${ }^{4}$ Classified specialist, ${ }^{5,6}$ Senior Resident

1-6Department of Diagnostic and Interventional Radiology, Army College of Medical Sciences and Base Hospital, Delhi, India

Corresponding Author: Abhishek Dwivedi, Graded Specialist, Department of Diagnostic and Interventional Radiology, Army College of Medical Sciences and Base Hospital, Delhi, India, Mobile: +918826384442, e-mail: abhishek232464@yahoo.com
}

radiological findings showed a significant relation with mortality in the study.

Keywords: Accident, Diffuse axonal injury, Subarachnoid hemorrhage (SAH), Traffic.

How to cite this article: Dhagat PK, Dwivedi A, Arora S, Singh SN, Singh S, Jain M. Spectrum of Radiological Findings on Noncontrast Computed Tomography Head in a Trauma Center with Cases of Acute Head Injuries. Journal of Medical Academics 2018;1(1):26-34.

Source of support: Nil

Conflict of interest: None

\section{INTRODUCTION}

The incidence of the is rising worldwide because of the rapid increase in the number and use of vehicles and rapid industrialization. In India, the majority of the population is of less than 60 years as compared with other developing conuntries. ${ }^{1}$ Since the head injuries are more grievous because of the loss of intellectual and cognitive functions resulting in patients dependability along with the additional burden of expenditure to the patients family for treatment unlike musculoskeletal trauma which is of more concern as the majority of the victims are young and productive age group. Hence head trauma in India is worrisome because of the significant amount of socioeconomic losses in India as compared with western counterparts. ${ }^{2,3}$ In India, road traffic accident is a major cause of head injuries (60\%) followed by falls (20 to $25 \%$ ) and physical violence $(10 \%){ }^{4}$

Noncontrast computed tomography (NCCT) head provides important clinical and surgical information in case of neurotrauma/traumatic brain injury (TBI). It can elaborate the severity, level, and prognosis of such injuries. Early diagnosis and management help in reducing the mortality and morbidity in these patients.

The CT scan is an important tool to diagnose intracranial lesions. ${ }^{5}$ Indications for CT scan might be different based on the clinical outcome measures, which could be the lesions related to the trauma or changes due to a surgical operation. ${ }^{6-9}$ However, because of the cost, time, and few complications of radiation, there has been significant debate about the indications for brain CT scan in a large number of neuro-trauma cases. ${ }^{10-12}$ 
The prompt and proper management of head injuries and their sequelae can significantly alter the course of disease especially within first 48 hours of the injury, neuroimaging techniques, which can determine the extent and presence of the injury and guide for the surgical planning along with minimally invasive interventions, play crucial roles in the acute management of the head injuries. ${ }^{13}$ Neuroimaging also can be important for the chronic management of head injuries, identifying their chronic sequelae, determining the prognosis, and guiding for proper rehabilitation.

\section{Indication for Noncontrast Computed Tomography Head}

\section{Glasgow coma scale}

The Glasgow coma scale (GCS) is a scale which rates the patient's level of consciousness from 3 (worst) to 15 (no impairment) based on the ability to open eyes, talk, and move, is commonly used to assess the severity of head injury. Few studies have suggested that score below 15 warrants neuro-imaging however other have suggested imaging if the GCS is below $13 .{ }^{14-18}$

\section{Vomiting and Headache, Amnesia}

Based on the New Orleans criteria, all TBI patients with a headache or vomiting and patients with transient amnesia should be imaged. ${ }^{19}$

\section{Ethanol or Drug Intoxication}

The New Orleans criteria have enlisted intoxication as an indication for imaging. It has been found that intoxicated patients with altered sensorium and impaired judgment are more likely to suffer from the severe grade of injuries. Chronic addiction is associated with brain atrophy hence making it more susceptible to insult. ${ }^{19}$

\section{Age (Extreme Ages)}

According to the New Orleans criteria, the head injury patients above 60 years of age should undergo imaging. ${ }^{19}$

\section{Others}

Anticoagulation and coagulopathies are debatable indications.

\section{Imaging in Acute Trauma-Computed Tomography versus Magnetic Resonance Imaging}

In the acute neurotrauma setting, early diagnosis and management may prevent secondary injuries from the complications. Adequate management can significantly improve mortality and morbidity of head injury patients with reducing hospital stay and health care costs. ${ }^{20,21}$ Neuroimaging helps in identifying cerebral and cranial abnormalities and determine their severity. It also gives the idea of operability to the surgeon, especially when complete neurological examinations cannot be performed due to poor patients condition. It is also important for surgical planning by providing better anatomic localization of the lesion and navigation information for neurosurgery. It helps in determining extracranial landmarks for better planning in the skin incision and guiding placement of burr holes when required. Imaging also helps in providing information on prognostic indicators, which may help in deciding the mode of management. ${ }^{22-24}$

Though anatomical imaging with MRI is more sensitive and accurate in the diagnosis of cerebral injuries in traumatic brain injuries however conventional CT is more easily available and cost-effective, requires shorter imaging time and is easier to perform on patients with ventilatory support or in traction or uncooperative patients, and hence is the initial imaging modality of choice during the first 24 hours after the injury. ${ }^{7,25-27}$ The newly used multi-detector $\mathrm{CT}$ has significantly reduced the time of scan and allows for quick selective rescanning of slices that are poorly acquired by motion artifact. ${ }^{28} \mathrm{CT}$ is also superior in evaluating bones and detecting acute subarachnoid or acute parenchymal hemorrhage. ${ }^{29}$

Presently because of the advantages of cost-effectiveness and convenience for use CT have limited the use of MRI in the acute management of traumatic brain injuries. In future when MRI becomes more available with more informative newer sequences along with less scanning time, this scenario may change. With the recent ongoing efforts, the use of MRI for a better understanding of the mechanisms of secondary injury in brain trauma may lead to preventative and preemptive treatments in the acute trauma setting. Eventually, the MRI brain may become a more useful tool for the early evaluation of acute traumatic brain injuries. ${ }^{30}$

This study primarily focuses on the NCCT radiological findings in acute head injuries, its use for early diagnosis and treatment to reduce mortality and morbidity in the traumatic head injuries patients.

\section{MATERIALS AND METHODS}

This was a retrospective observational study, conducted after clearance from the ethical committee. Out of total 7000 patients with history of head trauma with GCS $<15$, dizziness, severe headache followed by injury, nausea and vomiting, any episodes of orifices bleed were taken for NCCT evidence of head injuries and in whom surgical/clinical follow-up for final diagnosis was available 
between the duration of January 2014 to December 2016 a total of 518 cases were included by retrospective screening of the electronic report's data of these two years. The patients with a history of head/brain surgeries and associated with other body parts injuries were excluded as the clinical outcomes of these patients could not be judged due to multiple system involvement, and thus a total 518 patients were included in this study as cases of fresh head injury. The NCCT findings were recorded and tabulated in the study and correlated with the clinical outcomes during this study.

The patients were followed up clinically and by the radiological investigations based on the hospital data and follow up records from the hospital database for any deterioration of clinical features in this duration of the study including deterioration of GCS, associated meningitis, increased ICT, blood loss, shock, and death.

The radiological findings were reported by two junior radiologists of 4 years of experience and reviewed by two senior radiologists of 26 years of experience. The senior radiologists were kept unaware of the clinical background of the patients.

\section{Study protocol}

The NCCT acquisition was taken from C1 till the vertex. The study is done as per values and parameters (Table 1) for Somatom Emotion CT (16 slice MDCT) Siemens Medical Systems. ${ }^{31}$ The axial sections were reconstructed in coronal and sagittal planes to determine the findings in such patients.

\section{Statistical Analysis}

With the help of the Chi-square method different parameters were studied as age, sex, mode of trauma, radiological findings, personal history and biochemical parameters with the radiological findings

\section{RESULTS}

Out of the 518 patients, 355 were male, and 163 were female with age varies from 1 month to 92 years (Table 2). There were total 9 children and 43 adults.

Table 1: Distribution according to gender

\begin{tabular}{ll}
\hline Siemens & Emotion 16 \\
\hline Scan Mode & Sequential \\
Rotation Time (s) & 1.5 \\
Detector Configuration $(\mathrm{mm})$ & $6 \times 2$ \\
Pitch & - \\
KV & 130 \\
Quality.ref.mAs & 250 \\
CARE Dose4D & ON \\
CARE kV & - \\
\hline
\end{tabular}

The number of deaths noticed in the study was 13 with 12 out of 355 male and 1 out of 163 females. This result is statistically insignificant $(p$-value $=0.062)$. Fatal outcomes noticed $3.4 \%$ among males $0.6 \%$ among females and $2.5 \%$ among total cases (Table 3 ).

The history of head injuries reveals that 340 patients had road traffic accident (RTA), 141 had fallen and 37 had blunt trauma (Table 4).

On comparison of the males and females in the study it has been found that $74.9 \%$ males had history of road traffic accident (RTA), $18.9 \%$ had fallen and $6.2 \%$ had blunt trauma with while among the females it has been found that $45.4 \%$ had RTA, $45.4 \%$ had fall and 9.2\% had a history of blunt trauma with statistically significant ( $p$ values $=0.010$ ). The total contribution of each history in percentage is $65.6 \%$ total patients had RTA, $27.2 \%$ had, and $7.1 \%$ had a history of blunt trauma (Table 5).

Among the radiological findings contusion was found in $15.2 \%$ male and $3.1 \%$ females with statistically significant $(p$-value $=0.0010$ ) while it contributes $11.4 \%$ of all radiological findings (Table 6).

Diffuse axonal injury has been divided into three grades I, II and III. ${ }^{32}$ Among the radiological findings

Table 2: Age and gender distribution in this study

\begin{tabular}{|c|c|c|c|c|c|}
\hline & & Frequency & $\begin{array}{l}\text { Percent } \\
(\%)\end{array}$ & $\begin{array}{l}\text { Valid } \\
\text { percent } \\
(\%)\end{array}$ & $\begin{array}{l}\text { Cumulative } \\
\text { percent (\%) }\end{array}$ \\
\hline \multirow{3}{*}{ Valid } & Male & 355 & 68.5 & 68.5 & 68.5 \\
\hline & Female & 163 & 31.5 & 31.5 & 100.0 \\
\hline & Total & 518 & 100.0 & 100.0 & \\
\hline
\end{tabular}

Table 3: Contribution of each history of injury

Crosstab

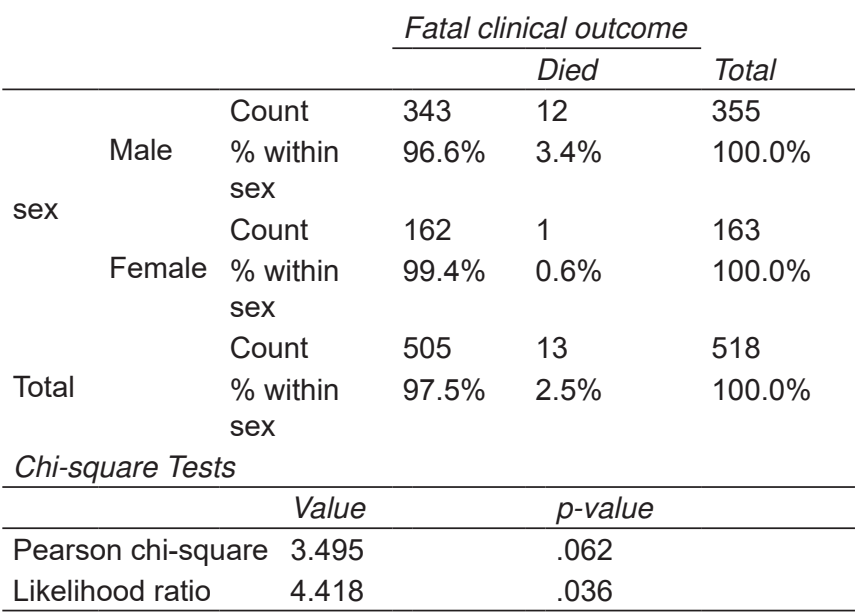

Table 4: Comparison of findings among males and females

\begin{tabular}{|c|c|c|c|c|c|}
\hline & & Frequency & $\begin{array}{l}\text { Percent } \\
\text { (\%) }\end{array}$ & $\begin{array}{l}\text { Valid } \\
\text { percent } \\
(\%)\end{array}$ & $\begin{array}{l}\text { Cumulative } \\
\text { percent (\%) }\end{array}$ \\
\hline \multirow{4}{*}{ Valid } & RTA & 340 & 65.6 & 65.6 & 65.6 \\
\hline & Fall & 141 & 27.2 & 27.2 & 92.9 \\
\hline & $\begin{array}{l}\text { Blunt } \\
\text { Trauma }\end{array}$ & 37 & 7.1 & 7.1 & 100.0 \\
\hline & Total & 518 & 100.0 & 100.0 & \\
\hline
\end{tabular}


Table 5: Gender wise distribution of history of head injuries Gender history Cross tabulation

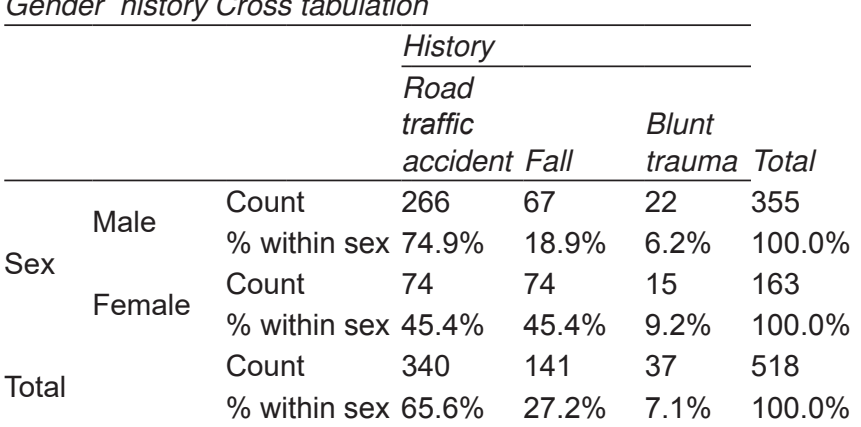

Chi-square tests

\begin{tabular}{lll}
\hline & Value & $p$-value \\
\hline Pearson chi-square & 45.130 & 0.0010 \\
Likelihood ratio & 43.866 & 0.0010 \\
\hline
\end{tabular}

diffuse axonal injury (DAI) of grade I were found among $0.3 \%$ and grade II among $2 \%$ of the cases in male and none in females. This was found statistically insignificant $(p$-value $=0.155)$. The DAI contributed $1.6 \%$ of total head injury cases (Table 7).

Among the radiological findings Subarachnoid hemorrhage (SAH) was found in $11.3 \%$ and $2.3 \%$ cases found SAH with associated intraventricular hemorrhage (IVH) among males and $4.9 \%$ only with SAH in females, this was found statistically significant $(\mathrm{p}$-value $=0.009)$ with total SAH in the cases found to be $10.8 \%$ (Table 8 ).

Table 6: Gender wise distribution of history of contusions

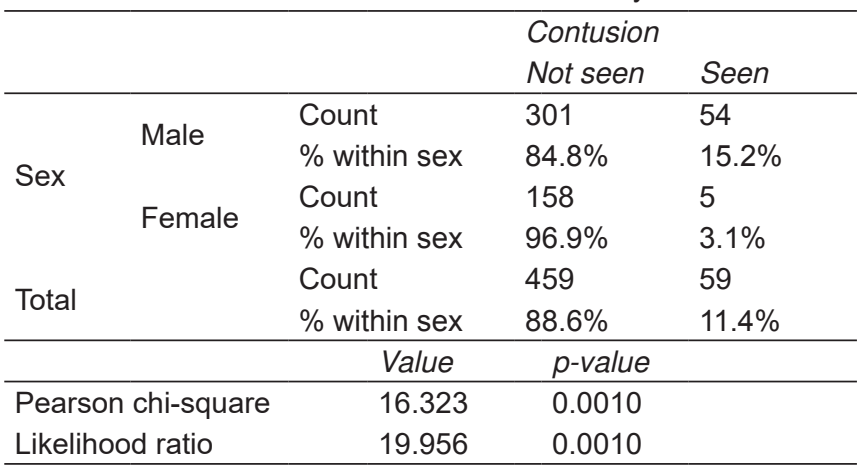

Table 7: Gender wise distribution of diffuse axonal injuries with grades

\begin{tabular}{|c|c|c|c|c|c|}
\hline \multicolumn{6}{|l|}{ Crosstab } \\
\hline & & \multicolumn{3}{|c|}{ Diffuse axonal injury } & \multirow[b]{2}{*}{ Total } \\
\hline & & & Grade & I Grade II & \\
\hline \multirow{3}{*}{ Male } & Count & 347 & 1 & 7 & 355 \\
\hline & $\begin{array}{l}\% \text { within } \\
\text { sex }\end{array}$ & $97.7 \%$ & $0.3 \%$ & $2.0 \%$ & $100.0 \%$ \\
\hline & Count & 163 & 0 & 0 & 163 \\
\hline \multirow[t]{2}{*}{ Female } & $\begin{array}{l}\% \text { within } \\
\text { sex }\end{array}$ & $100.0 \%$ & $0.0 \%$ & $0.0 \%$ & $100.0 \%$ \\
\hline & Count & 510 & 1 & 7 & 518 \\
\hline Total & $\begin{array}{l}\% \text { within } \\
\text { sex }\end{array}$ & $98.5 \%$ & $0.2 \%$ & $1.4 \%$ & $100.0 \%$ \\
\hline \multicolumn{6}{|c|}{ Chi-square Tests } \\
\hline & Value & $p$-value & & & \\
\hline $\begin{array}{l}\text { Pearson chi- } \\
\text { square }\end{array}$ & 3.731 & 0.155 & & & \\
\hline Likelihood ratio & 6.103 & 0.047 & & & \\
\hline
\end{tabular}

Among the radiological findings extradural hematoma/hemorrhage (EDH) was found in $8.7 \%$ male and $3.1 \%$ females with statistically significant ( $p$-value $=$ 0.019 ) while it contributes $6.9 \%$ of all radiological findings (Table 9).

Among the radiological findings the subdural hematoma/hemorrhage (SDH) was found in $15.5 \%$ male and $11.7 \%$ females with statistically insignificant $(\mathrm{p}$-value $=$ 0.247 ) while it contributes $14.7 \%$ of all radiological findings (Table 10).

The fractures of skull bones associated with head injuries were $25.9 \%$ and $3.1 \%$ found as single and multiple fractures among males and $18.4 \%$ single fracture with no evidence of multiple fractures in the females. This was found statistically significant ( $\mathrm{p}$-value $=0.012$ ). these fractures while it contributes $23.6 \%$ and $2.1 \%$ single and multiple fractures among all radiological findings respectively (Table 11).

The midline shift due to mass effect was found in $4.5 \%$ male and $6.1 \%$ females with statistically insignificant

Table 8: Gender wise distribution of Subarachnoid hemorrhages with and without intraventricular extension

\begin{tabular}{|c|c|c|c|c|c|}
\hline \multicolumn{6}{|l|}{ Crosstab } \\
\hline & & \multicolumn{4}{|c|}{ Sub arachnoid hemorrhage } \\
\hline & & \multicolumn{2}{|c|}{ Not seen Seen } & $\begin{array}{l}\text { Seen } \\
\text { with intra- } \\
\text { ventricular } \\
\text { hemorrhage }\end{array}$ & Total \\
\hline & Count & 307 & 40 & 8 & 355 \\
\hline Male & $\begin{array}{l}\% \text { within } \\
\text { sex }\end{array}$ & $86.5 \%$ & $11.3 \%$ & $2.3 \%$ & $100.0 \%$ \\
\hline Sex & Count & 155 & 8 & 0 & 163 \\
\hline \multirow[t]{2}{*}{ Female } & $\begin{array}{l}\% \text { within } \\
\text { sex }\end{array}$ & $95.1 \%$ & $4.9 \%$ & $0.0 \%$ & $100.0 \%$ \\
\hline & Count & 462 & 48 & 8 & 518 \\
\hline Total & $\begin{array}{l}\% \text { within } \\
\text { sex }\end{array}$ & $89.2 \%$ & $9.3 \%$ & $1.5 \%$ & $100.0 \%$ \\
\hline \multicolumn{6}{|c|}{ Chi-square tests } \\
\hline & Value & \multicolumn{4}{|c|}{$p$-value } \\
\hline \multicolumn{2}{|c|}{ Pearson chi-square 9.478} & \multicolumn{4}{|c|}{0.009} \\
\hline \multicolumn{2}{|c|}{ Likelihood ratio $\quad 12.439$} & \multicolumn{4}{|l|}{0.002} \\
\hline
\end{tabular}

Table 9: Gender wise distribution of extradural hemorrhage

\begin{tabular}{|c|c|c|c|c|c|}
\hline \multicolumn{6}{|l|}{ Crosstab } \\
\hline & & & \multicolumn{2}{|c|}{$\begin{array}{l}\text { Extra-dural } \\
\text { hemorrhage }\end{array}$} & \multirow[b]{2}{*}{ Total } \\
\hline & & & & Yes & \\
\hline \multirow{2}{*}{ Male } & \multicolumn{2}{|c|}{ Count } & 324 & 31 & 355 \\
\hline & \multicolumn{2}{|c|}{$\%$ within sex } & $91.3 \%$ & $8.7 \%$ & $100.0 \%$ \\
\hline \multirow{2}{*}{ Female } & \multirow{2}{*}{\multicolumn{2}{|c|}{$\begin{array}{l}\text { Count } \\
\% \text { within sex }\end{array}$}} & 158 & 5 & 163 \\
\hline & & & $96.9 \%$ & $3.1 \%$ & $100.0 \%$ \\
\hline \multirow{2}{*}{ Total } & \multirow{2}{*}{\multicolumn{2}{|c|}{$\begin{array}{l}\text { Count } \\
\% \text { within sex }\end{array}$}} & 482 & 36 & 518 \\
\hline & & & $93.1 \%$ & $6.9 \%$ & $100.0 \%$ \\
\hline \multicolumn{6}{|c|}{ Chi-square tests } \\
\hline \multicolumn{3}{|r|}{ Value } & \multicolumn{2}{|c|}{$p$-value } & \\
\hline \multirow{2}{*}{\multicolumn{2}{|c|}{ Pearson chi-square }} & 5.543 & \multicolumn{2}{|c|}{0.019} & \\
\hline & Likelihood ratio & 6.360 & \multicolumn{2}{|c|}{0.012} & \\
\hline
\end{tabular}


Table 10: Gender wise distribution of Subdural hemorrhages/ hematoma

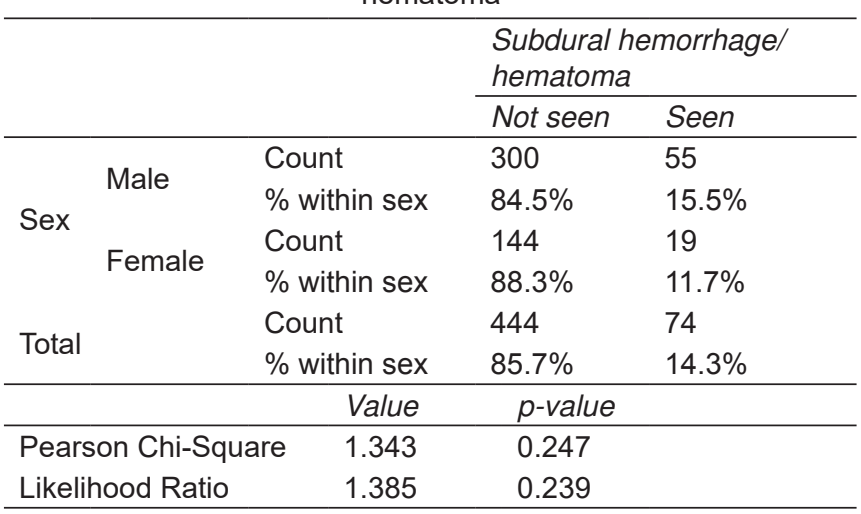

$(p$-value $=0.247)$ while it contributes $5 \%$ of all radiological findings(Table 12).

The scalp hematoma associated with a head injury was found in $8.7 \%$ male and $24.5 \%$ females with statistically insignificant ( $\mathrm{p}$-value $=0.001$ ) while it contributes $13.7 \%$ of all radiological findings (Table 13 ).

The mean age of presentation is 39.97 years, median 38 years and standard deviation of 20.08 (Table 14).

Table 11: Crosstab

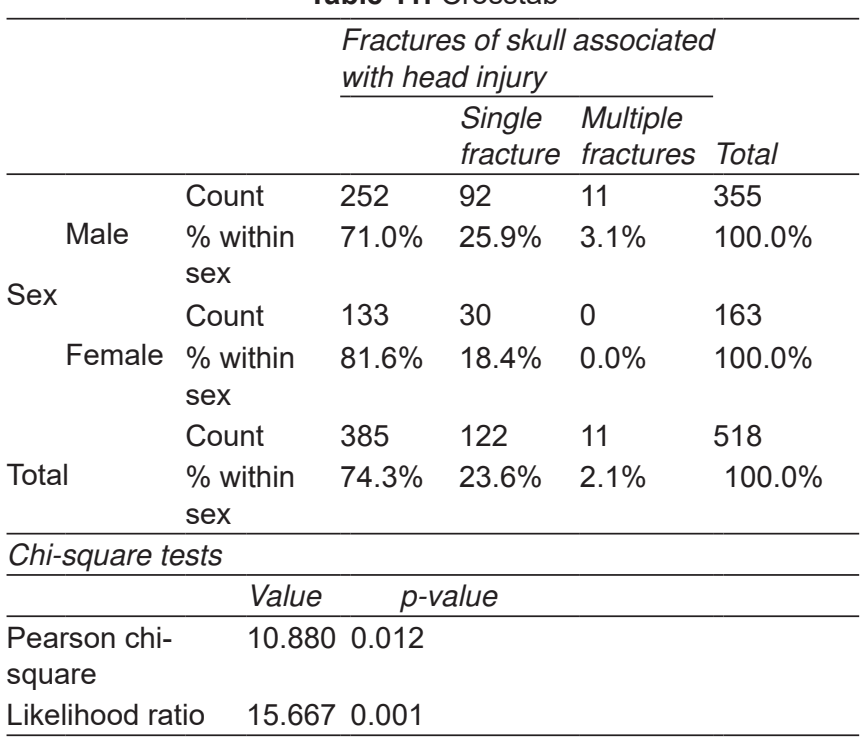

Table 12: Gender wise distribution of midline shift

\begin{tabular}{|c|c|c|c|c|}
\hline \multicolumn{5}{|c|}{ Midline_shift-crosstabulation } \\
\hline & & \multicolumn{2}{|c|}{ Midline_shift } & \multirow[b]{2}{*}{ Total } \\
\hline & & Present & Absent & \\
\hline & Count & 16 & 339 & 355 \\
\hline Male & $\begin{array}{l}\% \text { within } \\
\text { sex }\end{array}$ & $4.5 \%$ & $95.5 \%$ & $100.0 \%$ \\
\hline \multirow[b]{2}{*}{ Female } & Count & 10 & 153 & 163 \\
\hline & $\begin{array}{l}\% \text { within } \\
\text { sex }\end{array}$ & $6.1 \%$ & $93.9 \%$ & $100.0 \%$ \\
\hline & Count & 26 & 492 & 518 \\
\hline Total & $\begin{array}{l}\% \text { within } \\
\text { sex }\end{array}$ & $5.0 \%$ & $95.0 \%$ & $100.0 \%$ \\
\hline \multicolumn{5}{|c|}{ Chi-square tests } \\
\hline \multicolumn{4}{|c|}{ Value $p$-value } & \\
\hline \multicolumn{2}{|c|}{ Pearson chi-square } & \multicolumn{2}{|c|}{0.431} & \\
\hline \multicolumn{2}{|c|}{ Likelihood ratio } & 0.601 & 0.438 & \\
\hline
\end{tabular}

The cases associated with $>4$ radiological findings have more associated fatal outcomes with a relative risk of 35 as compared with the cases with $<4$ radiological findings (Table 15). This is statistically significant (p-value $=0.0001$ ).

\section{DISCUSSION}

The results of the study demonstrate that the NCCT head is an important and very useful investigation in the case of head injury patients as it provides an early diagnosis and thus early treatment in the minimum scan time.

The present study states that most of the cases had presented with a history of road traffic accident followed by fall and blunt trauma respectively. The radiological findings in the study show that fracture of the skull bones is the most common radiological finding followed by $\mathrm{SDH}$, scalp hematoma, contusion, SAH, EDH, midline shift and rarest is diffuse axonal injury (Figs 1 to 5). A total of $2.5 \%$ of the cases died, later on, follow-up. The cases with fatal outcomes had multiple radiological findings, and thus study suggests cases with more radiological findings had associated fatal outcomes. The study reveals that the contusion, $\mathrm{SAH}, \mathrm{EDH}$, fractures of skull bones

Table 13: Gender wise distribution of scalp hematoma

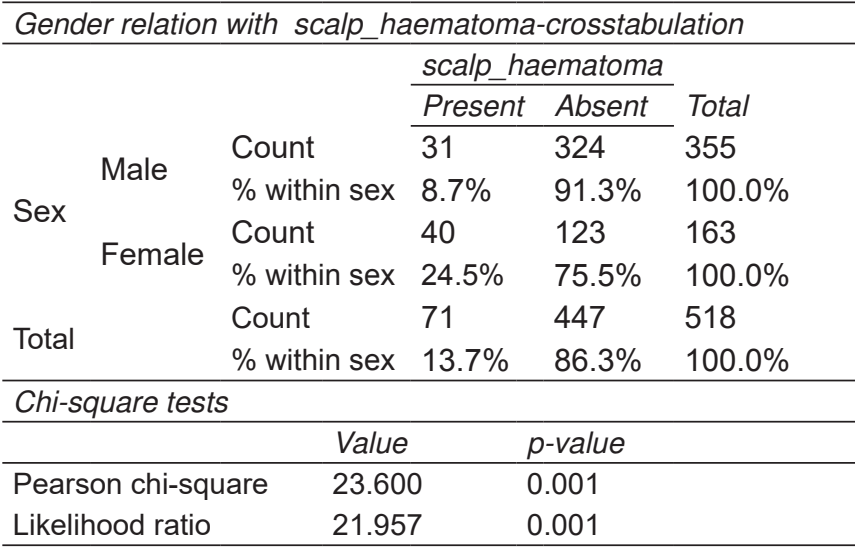

Table 14: Fatal outcomes and relation with radiological findings Statistics

\begin{tabular}{|c|c|c|}
\hline Age & & \\
\hline $\mathrm{N}$ & Total & 518 \\
\hline Mean & & 39.97 \\
\hline Median & & 38.00 \\
\hline Std. deviation & & 20.081 \\
\hline Range & & 95 \\
\hline Minimum & & 1 \\
\hline Maximum & & 96 \\
\hline
\end{tabular}

Table 15: Fatal outcomes and relation with radiological findings

\begin{tabular}{lllll}
\hline $\begin{array}{l}\text { Radiological } \\
\text { findings }\end{array}$ & $\begin{array}{l}\text { Cases } \\
\text { died }\end{array}$ & $\begin{array}{l}\text { Cases } \\
\text { survived }\end{array}$ & total & Calculations \\
\hline$>4$ & 10 & 35 & 45 & Relative risk $=35.44$ \\
$<4$ & 3 & 470 & 473 & Relative risk $=0.035$ \\
Total & 13 & 505 & 518 & p-value 0.0001 \\
\hline
\end{tabular}




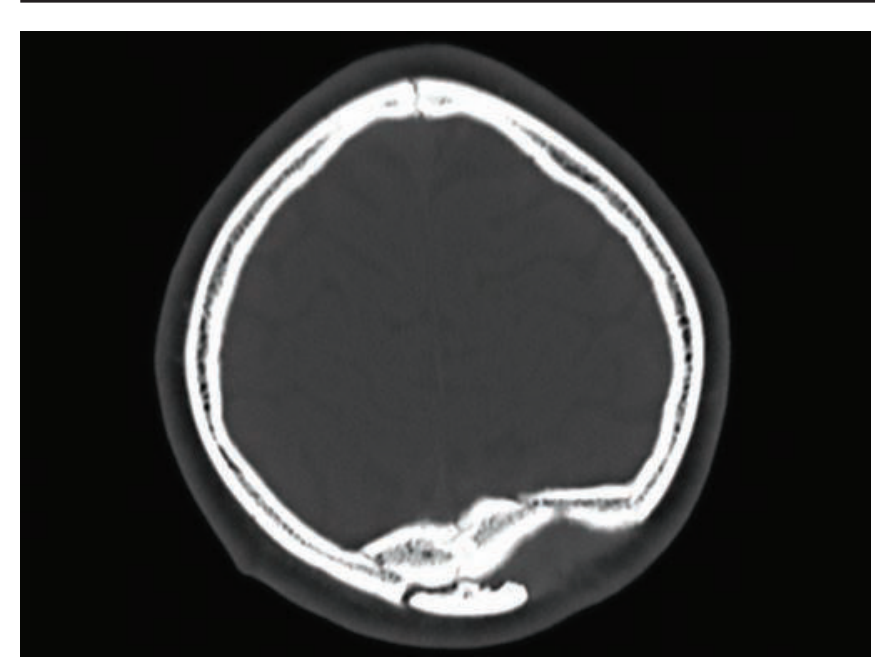

Fig. 1: 16-year female with history of fall from height axial section in bone window shows a depressed fracture of parietal bone

and scalp hematoma are more commonly seen in males as compared to females in the study. However, no gender predilection is statistically proven for fatal outcomes/ mortality in the cases. The cases with more radiological findings have shown more relative risk for fatal outcomes than the lesser radiological findings.

A study of Sekhar et al. included 791 total head injury cases with $569(72 \%)$ males and $222(28 \%)$ females. The average age of the cases is 24 years. The commonest mode of injury included fall from height $(56 \%)$ caused traumatic brain injury (TBI) followed by road traffic injury (RTI). ${ }^{33}$

During the radiological examination of other body parts about $11 \%$ revealed injuries. Good outcome noticed in $4 / 5$ th cases while $1 / 5$ th cases died later. The factors correlated with poor outcomes were the presence of injuries to other body parts proved radiologically, poor Glasgow coma scale (GCS), associated abnormalities in the cranial nerve, plantar and pupillary reflexes found during the examination.

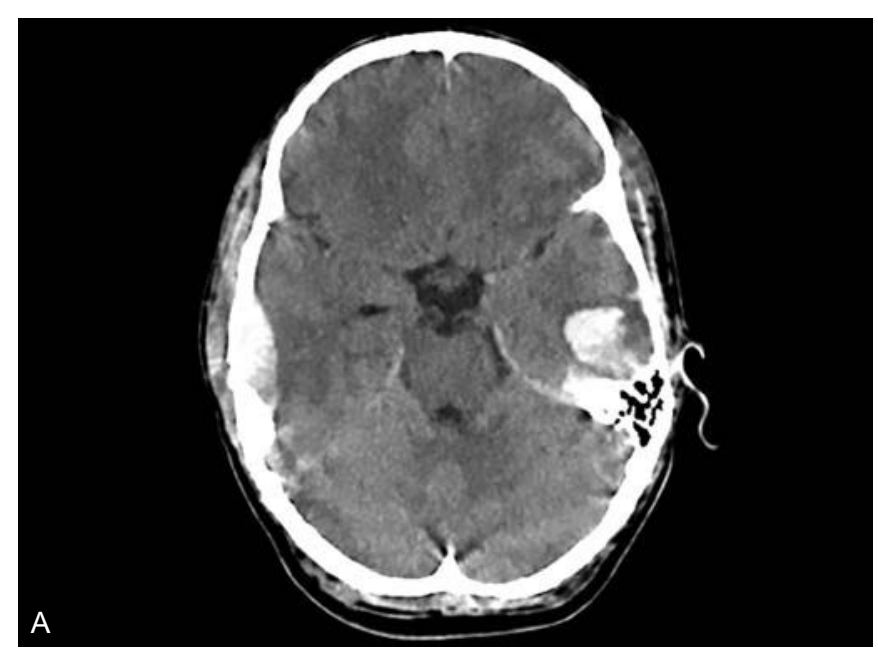

As compared with the above study, our study found that the average age is 39 years. The commonest mode of injury included road traffic accident $(65.6 \%)$ followed by fall $(27.2 \%)$ and trauma $(7 \%)$.

Mortality was associated with the cases had $>4$ radiological findings in the brain than the cases with $<$ 4 radiological findings. The cases died later were hardly $2.5 \%$ of the total cases (13 cases died out of 518 )

Another study by Sachin et al. included 100 patients with 76 male and 24 females with age predominantly of the elderly patients of mean age $63.5 \pm 4.64$ years. Among total the thirteen patients had an unknown history at the time of presentation. This study included only severe head injury patients with post-resuscitation GCS of < 8. All these patients were intubated in the during the emergency management with poor neurological status. In these patients, the RTA was the most common mode of injury (72\%). CT scan revealed acute $\mathrm{SDH}$ in the majority of the patients (53\%), followed by cerebral contusion (53\%), SAH (20\%), DAI (11\%) and EDH (10\%). Associated comorbidities included diabetes, coronary artery disease, hypertensive history, and alcoholic liver disease. The associated spinal injury was observed in $1 / 10$ th of the patients followed by abdominal solid organ injury and pneumothorax. Overall mortality in this study was 70\%. The factors associated with unfavorable outcome were mean time interval of onset of injury to the intervention, associated comorbidities, associated spinal, mechanical/ orthopedic injuries, abdominal injuries and associated SAH on CT head ( $p$-value $<0.05$ ). Ventilator-associated pneumonia led septicemia was the commonest postoperative cause of death in these cases. ${ }^{34}$ As compared with the above study, our study found that the RTA was the most common mode of injury. The mean age of the cases was 39 . The commonest radiological finding in our study was a fracture of skull bones followed by

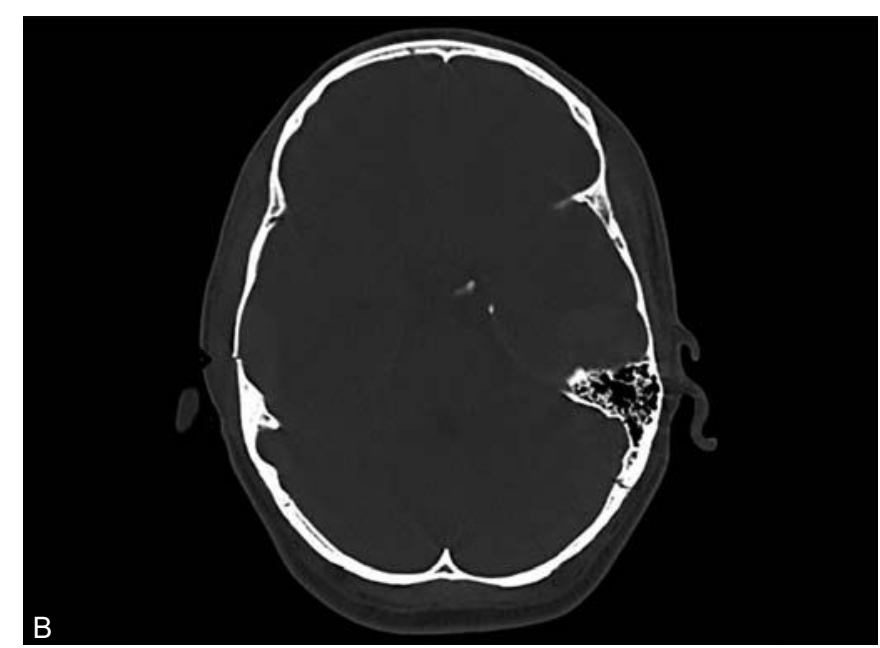

Figs $2 A$ and B: 28 years male met with a road traffic accident. (A) Axial section brain window showing right side EDH, scalp edema with underlying left temporal lobe hemorrhagic contusion; (B) Axial section bone window showing fracture of right temporal bone(arrow head) 


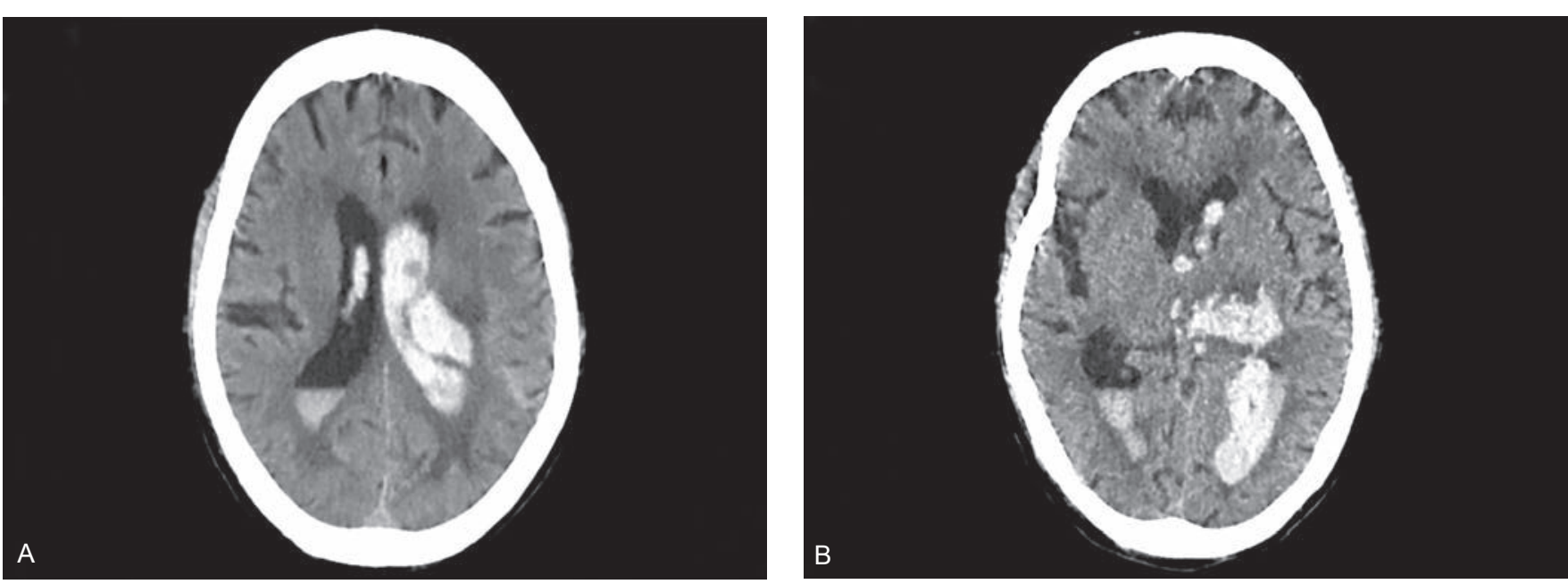

Figs $3 A$ and B: 70 year old female had a history of fall. This patient died later due to multiple organ dysfunction syndrome. (A) Axial section in brain window show IVH in the bilateral lateral with SAH at the left parietal sulcal spaces; (B) Axial section in brain window show IVH in bilateral lateral and 3rd ventricle, scalp edema in right frontal scalp with a midline shift of $6 \mathrm{~mm}$ toward right
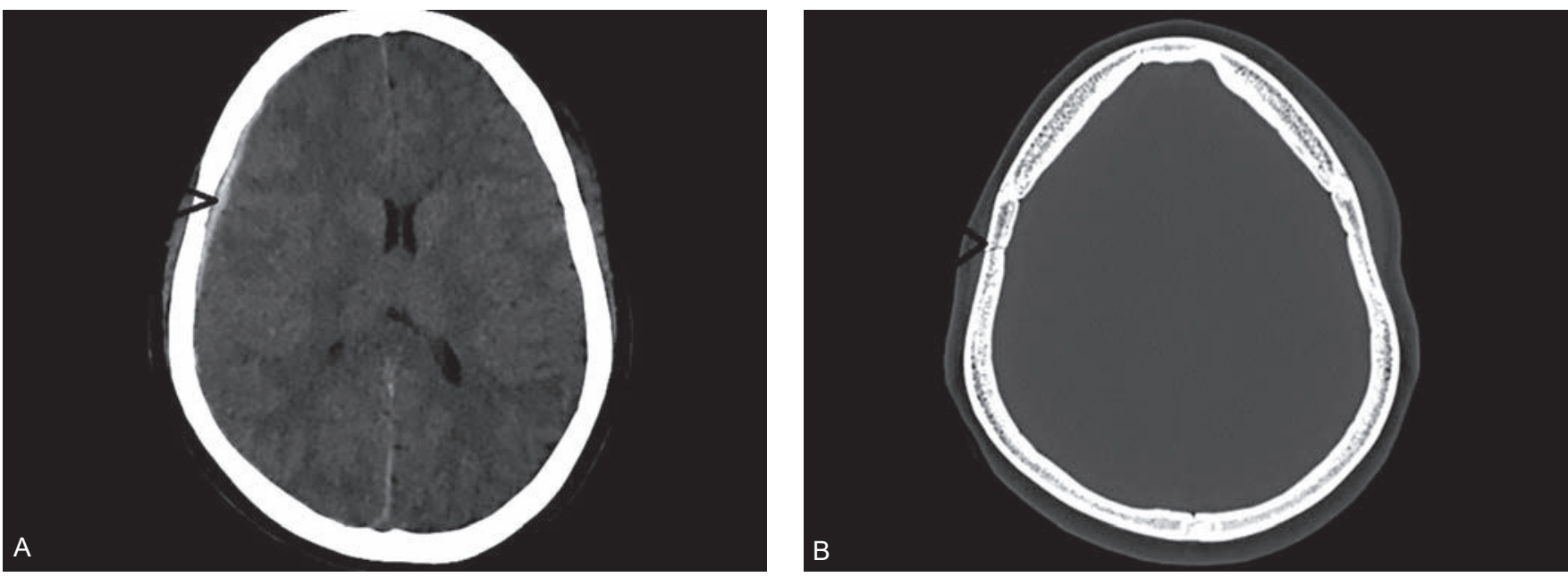

Figs 4A and B: 30 year old female with history of RTA. (A) Axial image in brain window shows SDH (arrow head); (B) Axial section in bone window show a fracture of right parietal bone is seen (arrow head). Scalp edema is seen on bilateral frontal scalp

$\mathrm{SDH}$. The study is following the pattern from the study of Sachin et al. for the mode of injuries, i.e., both studies had RTA as the commonest mode of injury, however, the radiological findings are not following the pattern. However, the differences among the studies with the present one could be are explained on the basis of the difference in the number of total patients, selection of the elderly age groups in the study of Sachin et al., exclusion of the patients with associated comorbidities and associated other part injuries in our study.

In this study included 518 patients among this 13 cases died-5 died due to excessive hemorrhage and shock, 4 died later due to hemorrhage brainstem compression, and respiratory failure and 4 died of sepsis. The interventions are done for managing these conditions as craniotomy and drainage has prevented such patients from these complications in the majority of the patients.

\section{Limitation of this study}

Few patients were excluded from the study due to associated comorbidities and associated other body part inju- ries however we had significant scope for studying such patients for better assessment of the effect of other than head injuries in neurotrauma patients and its application for preventing future mortality of such patients. The patients selected were not uniformly divided based on the age groups, gender, and mode of trauma. The radiation hazards associated could not be avoided.

\section{CONCLUSION}

The patients with acute head injury always have a risk for various complications. However, the early use of NCCT head helps in early diagnosis with triage and prompt treatment. The NCCT head has been found normal on few occasions but in such cases due to long procedure time and interferences of many life support instruments in the magnetic field makes the role of MRI limited otherwise in the majority of the emergency conditions management is mainly done by the findings of NCCT head. Similarly, on various postoperative conditions and critically ill patients in whom the crucial time of management is decisive the 

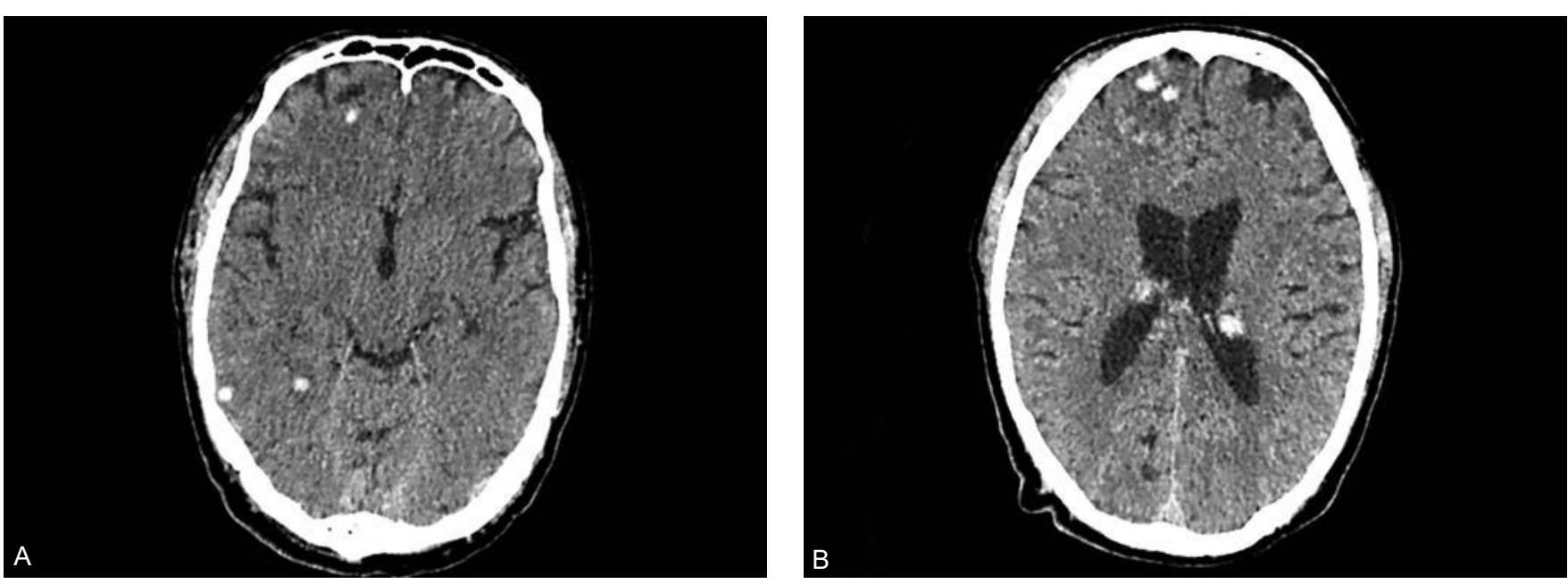

Figs 5A and B: 29 year old male with history of RTA. (A) Axial section in brain window shows multiple, discrete areas of hyperdensity with surrounding hypodensity seen at gray white matter interfaces in right frontal and parietal lobes of cerebrum sugestive of DAl; (B) Axial section in brain window shows multiple, discrete areas of hyperdensity at right frontal cortex and bilateral thalamoganglionic regions suggestive of DAI

NCCT head is a preferred modality due to the swiftness and superior soft tissue appreciation as compared with radiographic imaging. MRI is a tedious procedure, and solely for radiological findings, a critically ill patient with various life supports cannot be exposed to MRI if enough information can be achieved from a quick NCCT imaging procedure.

\section{ACKNOWLEDGMENT}

Authors would like to thank Dr Kumar, faculties of Army Hospital Research and Referral-Dr Banerjee, Dr Sreedhar, Dr Singh, Dr Rastogi, Dr Singh, Dr Uday Bhanu under whom I have learned the basics of radiology are my constant source of inspiration. Their continuous motivation and valuable guidance have led them to proceed for this publication.

\section{REFERENCES}

1. Park K. Preventive medicine in obstetrics, paediatrics and geriatrics. Text book of Preventive and Social Medicine, 18 eds. 2005:434.

2. Samabasivan M. Epidemiology of Neurotrauma. Neurology and Prevention. Neurol India (Supl)1991;43:9-15.

3. Ramamurthi B. Road accidents, Epidemiology and Prevention. Neurol India (Supl) 1991;43:9-15.

4. Gururaj G. Epidemiology of traumatic brain injuries: Indian scenario. Neurol Res. 2002;24:24-28.

5. Stein SC, Ross SE. Minor head injury: A proposed strategy for emergency management. Ann Emerg Med. 1993;22:11931196.

6. Smits M, Dippel DW, de Haan GG, Dekker HM, Vos PE, Kool DR, et al. Minor head injury: Guidelines for the use of CT - A multicenter validation study. Radiology. 2007;245: 831-838.

7. Miller EC, Holmes JF, Derlet RW. Utilizing clinical factors to reduce head CT scan ordering for minor head trauma patients. J Emerg Med. 1997;15:453-457.
8. Haydel MJ, Preston CA, Mills TJ, Luber S, Blaudeau E, DeBlieux PM. Indications for computed tomography in patients with minor head injury. N Engl J Med. 2000;343:100-105.

9. Stiell IG, Wells GA, Vandemheen K, Clement C, Lesiuk H, Laupacis A, et al. The Canadian CT Head Rule for patients with minor head injury. Lancet. 2001;357:1391-1396.

10. Abdul Latip LS, Ahmad Alias NA, Ariff AR, Shuaib IL, Abdullah J, Naing NN. CT scan in minor head injury: A guide for rural doctors. J Clin Neurosci. 2004;11:835-839.

11. Ono K, Wada K, Takahara T, Shirotani T. Indications for computed tomography in patients with mild head injury. Neurol Med Chir (Tokyo) 2007;47:291-297.

12. Shackford SR, Wald SL, Ross SE, Cogbill TH, Hoyt DB, Morris JA, et al. The clinical utility of computed tomographic scanning and neurologic examination in the management of patients with minor head injuries. J Trauma. 1992;33:385-394.

13. Hoyt DB, Holcomb J, Abraham E, Atkins J, Sopko G. Working Group on Trauma Research Program Summary Report: National Heart Lung Blood Institute (NHLBI), National Institute of General Medical Sciences (NIGMS), and National Institute of Neurological Disorders and Stroke (NINDS) of the National Institutes of Health (NIH), and the Department of Defense (DOD). J Trauma 57: 410-415, 2004

14. Ingedrigsten T, Romner B, Kock-Jensen C. Scandinavian guidelines for initial management of minimal, mild, and moderate head injuries. The Scandinavian Neurotrauma Committee. J Trauma 2000;48:760-6.

15. Stein SC, Ross SE. the values of computed tomographic scans in patients with low risk head injuries. Neurosurgery 1990;26:638-640.

16. Feuerman T, Wackym PA, Gade GF, Becker DP. Value of skull radiography, head computed tomographic scanning, and admission for observation in cases of minor head injury. Neurosurgery 1988;22:449-453.

17. Stein SC, O'Malley KF, Ross SE. Is routine computed tomography scanning too expensive for mild head injury? Ann Emerg Med 1991;20:1286-89.

18. Shackford SR, Wald SL, Ross SE, Cogbill TH, Hoyt DB, Morris JA, et al. the clinical utility of computed tomographic scanning and neurological examination in management of patients with minor head injuries. J Trauma 1992;33:385-394. 
19. Haydel MJ, Preston CA, Mills TJ, Luber S, Blaudeau E, DeBlieux PM, Indications for computed tomography in patients with minor head injury. N Engl J Medial 2000;343:100105.

20. Watts DD, Hanfling D, Waller MA, Gilmore C, Fakhry SM, Trask AL. An evaluation of the use of guidelines in prehospital management of brain injury. Prehosp Emerg Care 2004;8:254261.

21. Fakhry SM, Trask AL, Waller MA, Watts DD. Management of brain injured patients by an evidence based medicine protocol improves outcomes and decreases hospital charges. J Trauma 2004;56:492-499.

22. Chesnut RM. Implications of the guidelines for the management of severe head injury for the practicing neurosurgeon. Surgical Neurol 1998;50:187-193.

23. Bullock R, Chesnut RM, Clifton G, Ghajar J, Marion DW, Narayan RK, et al. Guidelines for the management of severe head injury. Brain Trauma Foundation. Eur J Emerg Med 1996; 3:109-127.

24. Chesnut RM, Marshall LF, Klauber MR, Blunt BA, Baldwin $\mathrm{N}$, Eisenberg HM, et al, The role of secondary brain injury in determining outcome from severe head injury. J Trauma 1993; 34:216-222.

25. Kelly AB, Zimmerman RD, Snow RB, Gandy SE, Heier LA, Deck MD. Head trauma: comparison of MR and CT-experience in 100 patients. AJNR Am J Neuroradiol 1988;9:699708.
26. Ahmadi J, Destian S. Head trauma. Top Magn Reson Imaging 1989;2:17-24.

27. Glauser J. Head injury: which patients need imaging? Which test is best? Cleve Clin J Med 2004;71:353-357.

28. Jones TR, Kaplan RT, Lane B, Atlas SW, Rubin GD. Singleversus multi-detector row $\mathrm{CT}$ of the brain: quality assessment. Radiology 2001;219:750-755.

29. Yealy DM, Hogan DE. Imaging after head trauma. Who needs what? Emerg Med Clin North Am 1991;9:707-717.

30. Pirko I, Fricke ST, Johnson AJ, Rodriguez M, Macura SI. Magnetic resonance imaging, microscopy, and spectroscopy of the central nervous system in experimental animals. NeuroRx 2005;2:250- 264.

31. AAPM guidelines, Adult Routine Head CT protocols Version 2.0. 2016.

32. Adams JH, Doyle D, Ford I, Gennarelli TA, Graham DI, Mclellan DR. Diffuse axonal injury in head injury; Definition, diagnosis and grading, Histopathology. 1989;(1):49-59.

33. Shekhar C, Gupta LN, Premsagar IC, Sinha M, Kishore J. An epidemiological study of traumatic brain injury cases in a trauma centre of New Delhi(India), J Emerg Trauma Shock 2015;8:131-9.

34. Borkar SA, Sinha S, Agrawal D, Satyarthee DG, Gupta D, MahapatraA K. Severe head injury in the elderly: risk factor assessment and outcome analysis in a series of 100 consecutive patients at a Level 1 trauma centre, Indian Journal of Neurotrauma 2011;8(2): 77-82. 